\title{
Recent History of Ischaemic Heart Disease and Duodenal Ulcer in Doctors
}

\author{
T. W. MEADE, ${ }^{*}$ B.M., M.R.C.P.; T. H. D. ARIE, $\dagger$ M.A., B.M., D.P.M. \\ M. BREWIS, ${ }^{*}$ M.D. ; D. J. BOND, F.I.A. ; J. N. MORRIS,* D.SC., F.R.C.P., D.P.H.
}

Brit. med. F., 1968, 3, 701-704

\begin{abstract}
Summary : Data are presented on the incidence of $\checkmark$ ischaemic (coronary) heart disease and duodenal ulcer among the several thousand male medical practitioners aged 35-64 holding immediate sickness benefit policies with the Medical Sickness Annuity and Life Assurance Society Limited. Three periods are considered : 1947-50, 1957-60, and 1961-5.

The incidence of first clinical episodes of ischaemic heart disease in the doctors altered little between 1947-50 and 1957-60 but increased in 1961-5. Comparison of the late 1940 s with the early 1960 s shows a $60 \%$ rise of incidence at ages $45-54$ but little change at other ages. Cases first presenting as "sudden" death increased between 1947-50 and 1961-5 by $111 \%$ at $45-54$, and again changed little at 55-64. In two other occupational groups that have been studied-bus conductors and insurance salesmen-the increase of incidence was greater than for the doctors at 45-54 and it occurred also over 55 years of age. The increase from 1947-50 to 1961-5 in mortality during all episodes of ischaemic heart disease was the same in the doctors as in the male population of England and Wales at $45-54$, but at 55-64 it was less.
\end{abstract}

The results in the doctors are not due to alterations over the period in length of sickness absence, or underwriting policy, or of the nomenclature used on the certificates.

Well-documented changes in the smoking habits of doctors may be partly responsible for what appears to have been a relatively favourable experience of ischaemic heart disease from 1947-50 to 1961-5, especially at ages 55-64.

Incidence of duodenal ulcer at ages 35-64 declined steadily in this population of doctors from 1947-50 to 1961-5. The decline is very likely to be real.

\section{Introduction}

We report a study of ischaemic heart disease and duodenal ulcer in one of the very few populations in this country for which there are incidence data-that is, of new cases as they present. This population comprises the male doctors aged 35-64 holding policies for immediate sickness benefit with the Medical Sickness Annuity and Life Assurance Society Limited. A previous report gave a detailed account of the incidence of ischaemic heart disease in these doctors in 1947-50 (Morris, Heady, and Barley, 1952), and here we deal with more recent experience up to and including 1965. Methods in the present study were identical with those used previously-all documents that did or might refer to cardiovascular disease were scrutinized by at least two of us. In addition, we have now examined the incidence of duodenal ulcer.

\footnotetext{
- Medical Research Council's Social Medicine Research Unit, London School of Hygiene and Tropical Medicine, London W.C.1. t Senior Lecturer in Social Medicine, London Hospital Medical College,
London E.1.

₹ Actuary, Medical Sickness Annuity and Life Assurance Society Limited.
}

There is much to suggest that doctors have changed some of their personal habits in recent years. It is certain that fewer are smoking cigarettes (Doll and Hill, 1964), and there is a general impression that many are taking more exercise and have altered their diet. It is thus of particular interest to inquire whether there have been any changes in the incidence of ischaemic heart disease. In the case of duodenal ulcer there is considerable evidence (Morris, 1964) that it is becoming less common, but whether this reflects a true decline in the frequency with which the disease is now arising can satisfactorily be settled only from population incidence rates-which have hitherto not been available.

\section{Ischaemic Heart Disease}

Table I gives average annual incidence rates for ischaemic heart disease for the three periods under consideration-namely, $1947-50,1957-60$, and 1961-5. "Incidence" is defined by a first episode (attack) of ischaemic heart disease causing absence from work for one week or more, or by death occurring within the first six days of a first episode ("sudden" death).

\begin{tabular}{|c|c|c|c|c|}
\hline Age & $1947-50$ & $1957-60$ & $1961-5$ & $\begin{array}{c}\text { Change in } \\
\text { Rate of } \\
1961-5 \\
\text { Series over } \\
\text { Rate for } \\
1947-50 \\
(\%)\end{array}$ \\
\hline $\begin{array}{l}35-39 \\
40-44 \\
45-49 \\
50-54 \\
55-59 \\
60-64\end{array}$ & $\begin{array}{rr}\overline{2} & (2) \\
2 \cdot 2 & (12) \\
3.4 & (21) \\
7.0 & (28) \\
11.9 & (33) \\
16.6 & (27)\end{array}$ & $\begin{array}{rr}\overline{1} & (4) \\
1.7 & (8) \\
3.5 & (18) \\
7.4 & (40) \\
10.9 & (59) \\
13.7 & (41)\end{array}$ & $\begin{array}{rr}1.4 & (8) \\
2.1 & (13) \\
6.4 & (39) \\
9.4 & (61) \\
10.7 & (69) \\
16.4 & (68)\end{array}$ & $\begin{array}{r}-5 \\
+88 \\
+34 \\
-10 \\
-1\end{array}$ \\
\hline Ave. population .. & 6,180 & 7,114 & 7,026 & \\
\hline Total new incidents & 123 & 170 & 258 & \\
\hline $\begin{array}{l}\text { Standardized* inci- } \\
\text { dence rates per } \\
1,000 \text { (ages 40-64) }\end{array}$ & $7 \cdot 3$ & $7 \cdot 1$ & 8.7 & \\
\hline
\end{tabular}

Figures in parentheses are actual numbers of new incidents, or fist clinica episodes, of ischaemic heart disease (all presentations).

Rates not calculated where there are fewer than five new episodes.

Standardized on the 1966 male home population of England and Wales. The differences between $1947-50$ and $1961-5$ are significant at $45-49(P<0.01)$

Two points emerge from Table $I$. The first is that rates at each age are very similar for 1947-50 and 1957-60. Secondly, there is a rise in incidence between 1957-60 and 1961-5. This has occurred at all ages except 55-59, and is especially marked at $45-49$; because of small numbers, rates at 35-39 are not shown throughout, but the actual number of new incidents at this age also rose. Overall, comparing the late 1940 s and the early 1960 s, there was a substantial rise of incidence $(65 \%)$ at $45-54$ but little change at other ages.

Table II shows rates for " sudden" deaths in the three series. The number of cases is smaller and the data have been amalgamated into three age groups. The main feature, again, is an increase (of $111 \%$ ) at $45-54$ years; the rate rose steadily between 1947-50 and 1961-5. 
TABLE II.-Mortality from "Sudden" Deaths (Within Six Days of First Clinical Presentation) from Ischaemic Heart Disease in Medical Practitioners, 1947-50, 1957-60, and 1961-5. Men Aged 35-64, Inclustve, Holding Policies for Immediate Sickness Benefit. Average Annual Rales per Thousan $x$

\begin{tabular}{c|c|c|c|c}
\hline Age & $1947-50$ & $1957-60$ & $1961-5$ & $\begin{array}{c}\text { Change in } \\
\text { Rate of } \\
1961-5 \text { Series } \\
\text { over Rate for } \\
1947-50(\%)\end{array}$ \\
\hline $\begin{array}{c}35-44 \\
45-54 \\
55-64\end{array}$ & $\begin{array}{c}0.5(5) \\
0.9\end{array}\left(\begin{array}{c}(9) \\
3.4(15)\end{array}\right.$ & $\begin{array}{c}1.3(1) \\
2 \cdot 6(22)\end{array}$ & $\begin{array}{c}1.9 \\
2.9(2)\end{array}$ & +111 \\
\hline Total new incidents & 29 & 37 & 57 & -15 \\
\hline
\end{tabular}

Figures in parentheses are actual numbers of new episodes (deatis in the first 6 days of the first clinical presentation).

Rates not calculated where there are fewer than five new episodes.

The differences between 1947-50 and 1961-5 are significant at 45-54 (P<0.05 but not at 55-64.

In view of the rise between 1957-60 and 1961-5 the latter series was examined more closely. In 1961-2 there were 101 new incidents -86 of non-fatal infarction or angina and 15 of "sudden" death. In 1964-5 there were 105 new incidents; 74 were of non-fatal infarction or angina and 31 of "sudden" death. (The populations at risk may be taken as identical for the two periods.) These changes are disturbing, but numbers are small and we must wait for the experience of 1966-7.

\section{Discussion}

There are some possible "technical" snags to these data. The nature and characteristics of the exposed populations may have altered between the late 1940s and the early 1960s. Thus in $1947-5035 \%$ of the population were aged 50-64, while in 1961-5 the corresponding figure was $48 \%$. There are two main reasons for this change in age structure. Firstly, the 1947-50 population had aged some 15 years by 1961-5. Secondly, the numbers of men applying for immediate sickness benefit policies declined slightly between 1957-60 and 1961-5, as seen in the "total populations" of Table I, though the overall number of all types of policies issued by the Society increased. We have, of course, calculated age-specific rates throughout. There is no practicable way of determining whether there may have been other important changes in the population over the period. The proportion of general practitioners has been remarkably constant.

We also have to allow for possible changes in nomenclature and diagnostic fashions which might influence incidence rates by leading to the inclusion of individuals at one time who might be excluded at another. The term "angina pectoris" was used in about $6 \%$ of new cases in the 1961-5 series, but in $17 \%$ of new cases in the 1947-50 series. However, this change has been offset by an increase since 1947-50 of certification of "myocardial ischaemia"; in fact, the terms "angina pectoris" plus " myocardial ischaemia" were used in the same proportion of new cases in 1961-5 as "angina pectoris" alone in 1947-50. If these are accepted as interchangeable, the distribution of the three main first clinical presentations altered little over the period. Thus in 1947-50 angina accounted for $17 \%$ of the new incidents, " coronary thrombosis," etc., with survival for more than six days for $59 \%$, and "sudden death" as already defined for $24 \%$. Corresponding figures for $1961-5$ are $18 \%$, $58 \%$, and $21 \%$ (the remaining $3 \%$ being due to other diagnoses occasionally made-for example, "coronary insufficiency," and "left ventricular failure due to ischaemic heart disease"). We feel, therefore, that neither changes in nomenclature nor in diagnostic fashion can account for changes in incidence over the years. (It may be remarked that the similarity of the proportions of "sudden" death in 1947-50 and 1961-5 makes it unlikely that doctors have derived any particular benefit from recent developments in coronary care, and the larger number of rapidly fatal incidents already described in 1964-5 than in 1961-2 is further evidence of this.) It should be said that although these deaths were defined as occurring within the first six days they mostly took place very quickly.

Another "technical" possibility is that doctors who first developed ischaemic heart disease in 1961-5 tended more, or less, frequently than their colleagues in 1947-50 to take less than a week off work, so that incidence rates, as we have defined them, would be spuriously different for 1961-5. In 1947-50 $80 \%$ of first absences for "angina" and $97 \%$ of first absences for " coronary thrombosis" lasted more than a month. Corresponding figures for $1961-5$ are $74 \%$ and $84 \%$. Changes in length of absence are thus unlikely to be the reason for changes in incidence rates.

We have considered also whether alterations during the period in underwriting practice towards doctors already suffering from hypertension or diabetes (or, theoretically, from ischaemic heart disease), and consequently in the readiness of such doctors to apply for policies, might have changed the population at risk and so influenced the incidence rates. The brief answer is that there has been only one important change: up to 1957 a doctor known or found to be diabetic on first applying for a policy could not subsequently claim for incapacity "due to or arising from " diabetes, whereas since 1957 full cover with the ability to claim for diabetes and its complications has usually been granted, subject to an additional premium. This change is probably too recent to have any bearing on the results of our study, but any slight influence which it might have had would be in the direction of overestimating the relative increase in incidence between 1947-50 and 1961-5.

None of these "technical" snags especially affect the 45-54year age group, in whom the only striking changes have occurred. Nearly all men first taking out immediate sickness benefit policies are under 45 .

In summary, then, we found almost no change in the doctors' experience of ischaemic heart disease between 1947-50 and 1957-60, but an increase; especially at ages 45-54, between $1957-60$ and 1961-5. To assess these results it is necessary to know what changes have occurred in other groups. There is no way of knowing how many of those whose deaths are certified to ischaemic heart disease in the Registrar General's Tables die in their first clinical episode; however, regardless of when death occurred, comparisons of total coronary mortality for the population as a whole and for the doctors are interesting. Thus Table III shows that between the late 1940s and early 1960 s the increases in mortality at 45-54 were similar. At 55-64, though there were increases in both groups, the rise among the doctors was only half that for the population as a whole.

TABLE III.-Total Mortality from Ischaemic Heart Disease* in (i) Medical Practitioners Holding Policies for Immediate Sickness Benefit and (ii) Male Population of England and Wales; 1947-50 and 1961-5. Men Aged 45-54 and 55-64. Average Annual Rates per Thousand

\begin{tabular}{|c|c|c|c|c|}
\hline & Age & $1947-50$ & $1961-5$ & $\begin{array}{c}\text { Increase in } \\
\text { Rate for } \\
1961-5 \text { ove } \\
\text { Rate for } \\
1947-50 \\
(\%)\end{array}$ \\
\hline Medical practitioners \{ & $\begin{array}{l}45-54 \\
55-64\end{array}$ & \multirow{2}{*}{$\begin{array}{c}1.6 \\
5.7 \\
(41) \\
1.1 \\
3.5\end{array}$} & \multirow{2}{*}{$\begin{array}{c}3.2 \\
8.3 \\
(128) \\
2.3 \\
6.5\end{array}$} & $\begin{array}{r}100 \\
46\end{array}$ \\
\hline $\begin{array}{l}\text { Male population of } \\
\text { England and W/ales }\end{array}$ & $\begin{array}{l}45-54 \\
55-64\end{array}$ & & & $\begin{array}{r}109 \\
86\end{array}$ \\
\hline
\end{tabular}

"Total mortality" includes all deaths from ischaemic heart disease-that is, in later recurrent episodes as well as in the first, and after the first 6 days of the ep
as well as within.

Figures for England and Wales from Registrar General's Annual Reviews.
Figures in parentheses are total numbers of deaths from ischaemic heart disease Figures in parentheses are total number

* See text for definition.

The figures in Table III refer to all deaths from arteriosclerotic heart disease, including coronary disease, and angina pectoris without mention of coronary disease-that is, International List of Causes of Death (I.C.D.) No. 94 in the Fifth Revision (1938) and No. 420 in the Sixth Revision (1948). The 
figures do not include deaths from myocardial degenerationthat is, I.C.D. No. 93c and 93d in the Fifth Revision and No. 422 in the Sixth Revision. Among the doctors, only one death was certified merely to "myocardial degeneration" in 1947-50, and one in 1961-5; we excluded these two cases. In the general population the term is or was used more commonly to describe deaths from chronic bronchitis, cor pulmonale, and hypertensive heart disease (Morris, 1955), and from pneumonia, venous and embolic disease, and cerebrovascular disease (Heasman and Lipworth, 1966), as well as from ischaemic heart disease. The inclusion in Table III of deaths certified as "myocardial degeneration" in the general population would reduce the increase between 1947-50 and 1961-5 to $60 \%$ at $45-54$ and to $20 \%$ at 55-64. Incidentally the doctors' figures show the importance of "sudden" death occurring in a first clinical episode in the total montality from ischaemic heart disease: 57 deaths (see Table II) out of 128 (see Table III).

We can make two further comparisons from data collected (in the course of other studies) by the Social Medicine Research Unit. Between 1949-52 and 1959-66 "sudden" death in male London Transport bus conductors at 45-54 from ischaemic heart disease rose by $160 \%$; at 55-64 it rose by $45 \%$. Secondly, in a group of insurance salesmen, between 1954-6 and 1958-60, total incidence of ischaemic heart disease rose by $63 \%$; at $55-59$ it rose by $130 \%$; these increases took place over a considerably shorter period than those in the doctors.

The comparisons we have just made leave much to be desired, but it appears reasonable to conclude that the doctors had a smaller increase of ischaemic heart disease between the late 1940 s and early 1960s than the average. That is to say, the doctors may have shown a rclative improvement compared with other people.

It is very difficult to assess the effects that changes in personal habits-for example, cigarette smoking-may have had on doctors' experience of ischaemic heart disease. A number of studies have shown that the effects of cigarette smoking vary with age, both for mortality (Doll and Hill, 1964 ; Hammond, 1966) and for non-fatal clinical disease (Spain and Nathan, 1961 ; Paul et al., 1963). In general, for a given level of smoking the effects are greater at 35-54 that at older ages. The bulk of the evidence linking cigarette smoking with various diseases accumulated between our first and second series-that is, between 1947-50 and 1957-60. It is at least plausible that part of the doctors' relative improvement in their experience of ischaemic heart disease is a result of their smoking less. We do not know how typical the doctors studied were of doctors as a whole vis-à-vis smoking (and other) habits; however, our total populations have been large.

\section{Duodenal Ulcer}

Duodenal ulcer appears to be declining, as judged by clinical experience, by mortality, by hospital admission rates for perforation and for "cold" surgery, and by certified incapacity to work (Morris, 1964). Taken together, these observations are likely to reflect a fall in the frequency with which the condition is arising in the population-that is, the incidence of the condition-rather than merely a decline in its severity. A study that has been specifically designed to study incidence is, however, the only certain method of investigating this point.

\section{Method}

Incidence was defined as a first episode of sickness lasting one week or more due to definite or possible duodenal ulcer, and all such cases were identified. Cases were classified as definite when the certificate referred directly to duodenal ulcer, or where there was reference to definite radiological evidence of duodenal ulcer. Into the category of possible duodenal ulceration we put (1) cases of haematemesis and/or melaena where the direct cause was not specifically given, and (2) a further small number of cases in which uncertain terminology nevertheless indicated likely duodenal ulcer-for example, duodenitis ; we also included cases of peptic ulcer where no further information was given. All cases certified as gastric ulcer were classified separately; there were too few in any of the periods to calculate rates.

\section{Results}

Three periods again are considered-that is, 1947-50, 1957-60, and 1961-5. As Table IV shows, there has been a fall in incidence of "definite" duodenal ulcer between 1947-50 and 1961-5 for all ages.

TABLE IV.-Incidence of Duodenal Ulcer in Medical Practitioners, 1947-50, 1957-60, and 1961-5. Men Aged 35-64, Inclusive, Holding Policies for Immediate Sickness Benefit. Average Annual Rates per Thousand

\begin{tabular}{|c|c|c|c|c|}
\hline Age & & $1947-50$ & $1957-60$ & $1961-5$ \\
\hline \multicolumn{5}{|c|}{ Incidence of Definite Duodenal Ulcer } \\
\hline $\begin{array}{l}35-44 \\
45-54 \\
55-64\end{array}$ & & $\begin{array}{ll}1.9 & (19) \\
2.5 & (26) \\
2.0 & (9)\end{array}$ & $\begin{array}{l}1.3(12) \\
1.0(11) \\
1.7(14)\end{array}$ & $\begin{array}{l}0.7 \quad(8) \\
1.0 \quad(12) \\
1.3 \quad(14)\end{array}$ \\
\hline Total new incidents & .. & 54 & 37 & 34 \\
\hline \multicolumn{2}{|c|}{$\begin{array}{l}\text { Standardized } * \text { incidence } \\
\text { rates per } 1,000 \text { (ages }\end{array}$} & $2 \cdot 1$ & 1.3 & $1 \cdot 0$ \\
\hline
\end{tabular}

\begin{tabular}{|c|c|c|c|c|}
\hline \multicolumn{5}{|c|}{ Incidence of Definite and Possible Duodenal Ulcer } \\
\hline $\begin{array}{l}35-39 \\
40-44 \\
45-49 \\
50-54 \\
55-59 \\
60-64\end{array}$ & & $\begin{array}{l}2.8(13) \\
2.9(16) \\
3.1(19) \\
4.2(17) \\
3.6(10) \\
-\quad(3)\end{array}$ & $\begin{array}{l}1.4(7) \\
2.6(12) \\
1.9(10) \\
3.0(16) \\
1.7 \quad(9) \\
4.0(12)\end{array}$ & $\begin{array}{l}1.3(7) \\
1.7(11) \\
1.3 \quad(8) \\
2.0(13) \\
1.5(10) \\
2.6(11)\end{array}$ \\
\hline Total new incidents & . & 78 & 66 & 60 \\
\hline $\begin{array}{l}\text { Standardized } \\
\text { rates per incider } \\
35-64 \text { ) }\end{array}$ & .. & $3 \cdot 1$ & $2 \cdot 4$ & 1.7 \\
\hline
\end{tabular}

Figures in parentheses are actual numbers of new incidents or first episodes of duodenal ulcer, etc.

Rates not calculated where there are fewer than five new episodes.

* Standardized on the 1966 male home population of England and Wales.

If "possible" cases are added to the "definite" it is quite clear again that there has been a substantial and steady fall.

\section{Discussion}

It is difficult to define the onset of any chronic disease, and in such conditions the definition of "incidence" must be operational. The definition we have used-the first claim to sickness benefit for duodenal ulcer-is reasonable; moreover, it did not alter over the period studied. Underwriting policy towards proposals from doctors with previous or present histories of duodenal ulcer, its complications, or severe recurring dyspepsia have also remained constant ; in these cases the policy has excluded benefit for sickness due to or arising from these conditions.

Some "technical " points to be borne in mind in interpreting the results have already been discussed (under "Ischaemic Heart Disease ") and so far as the denominator, or populations, are concerned the same comments apply. For the numeratorthat is, the cases ascertained-there are various possibilities to be considered. One is that diagnostic fashions may have altered and that doctors were less likely in 1961-5 to label a particular clinical picture as "duodenal ulcer" than in $1947-50$, or $1957-60$. With easy access to radiology throughout the period 1947-65 this seems unlikely. A related possibility is that terminology may have altered and that, for example, what was called "duodenal ulcer" in 1947-50 was called 
something else in 1961-5 ; this would have had the effect of artificially lowering incidence rates. Conclusively to settle this point is impossible. However, in the initial scanning of the records from which cases were identified all mentions of any kind of intra-abdominal pathology were extracted for examination, and we found no evidence at all of changes in terminology of the kind that would be needed to lower incidence rates.

A second possibility is that sickness absence for duodenal ulcer is becoming shorter. If there were an increase in instances where a doctor with a duodenal ulcer either had an absence of less than a week, or in which he was not away from work at all-perhaps because the condition is becoming milder-a misleading fall in rates might occur. Among the doctors, as for the general population (Morris, 1964), absences for duodenal ulcer tend to be long-presumably mainly for complications. In 1947-50 and 1957-60 the average length of absence for definite duodenal ulcer was 52 days ; in 1961-5 it was 43 days. It is unlikely that this decrease in length of absence could account for the decrease in incidence rates. Moreover, we have shown a trend in the fall of incidence rates between 1947-50, $1957-60$, and 1961-5; there is no corresponding trend in lengths of absence, the figure for the middle period being identical with 1947-50. Further, in $1947-50,8 \%$ of first absences for duodenal ulcer in the doctors were for less than two weeks and in 1957-60 and 1961-5 5\% and 6\% respectively. There is no evidence of a material change in the frequency of short absences.

We conclude that over the last 20 years there has been a true and substantial decline in the incidence of duodenal ulcer among these doctors. Our numbers of new cases and periods of observation are not enough to make possible a cohort study of the kind undertaken for mortality from duodenal ulcer by Susser (1967). Susser's view is that mortality has declined because successive cohorts have carried with them progressively less environmental exposure to factors causing duodenal ulcer. However, mortality is a poor indicator of secular trend in a disease with such a low case fatality. To explain why incidence should be declining involves considering, for example, whether other states may be increasing, thus providing alternative outlets for frustration, tension, anxiety, etc.

We wish to thank the Directors of the Medical Sickness Annuity and Life Assurance Society Limited for permission to examine the records of the Society, and for providing the "populations at risk." We are especially grateful to Dr. T. C. Hunt, Chief Medical Officer, and to Mr. R. G. Barley, General Manager. We are also grateful to Dr. J. A. Heady for his advice.

Requests for reprints should be addressed to Dr. T. W. Meade.

•

REFERENCES

Doll, R., and Hill, A. B. (1964). Brit. med. 7., 1, 1399, 1460.

Hammond, E. C. (1966). Nat. Cancer Inst. Monogr., No. 19, p. 127. Heasman, M. A., and Lipworth, L. (1966). Accuracy of Certification of Cause of Death. General Register Office, Studies on Medical and Population Subjects No. 20. H.M.S.O., London.

Morris, J. N. (1955). Med. Offr, 94, 251.

Morris, J. N. (1964). Uses of Epldemiology, 2nd ed. Edinburgh.

Morris, J. N., Heady, J. A., and Barley, R. G. (1952). Brit. med. 3.,

1, 503. et al. (1963). Circulation, 28, 20.

Paul, O., et al. (1963). Circulation, 28, 20. ${ }^{2}$. Amer. med. Ass., 177, 683.

Susser, M. (1967). Y. chron. Dis., 20, 435 .

\title{
Effects of Iron Overload on Ascorbic Acid Metabolism*
}

\author{
A. A. WAPNICK, $\dagger$ M.B., в.CH.; S. R. LYNCH, $\dagger$ м.B., в.CH. ; P. KRAWITZ, $\ddagger$ B.SC. \\ H. C. SEFTEL, $\S$ B.SC., DIP.MED.; R. W. CHARLTON,\| M.D., B.SC., M.R.C.P.ED. \\ T. H. BOTHWELL, M M.D., D.SC., F.R.C.P.
}

Brit. med. F., 1968, 3, 704-707

\begin{abstract}
Cummary : Studies of the ascorbic acid status in two subjects with idiopathic haemochromatosis and in 12 with transfusional siderosis showed that all had decreased levels of white cell ascorbic acid. The urinary excretion of ascorbic acid was also diminished in those subjects in whom such measurements were made. The administration of ascorbic acid was followed by only a small rise in the urinary ascorbic acid output, while the oxalic acid levels (measured in two subjects) showed a significant rise. These findings resemble those described in siderotic Bantu, and support the thesis that increased iron stores lead to irreversible oxidation of some of the available ascorbic acid.
\end{abstract}

\section{Introduction}

Iron overload resulting from prolonged exposure to a high dietary iron intake is extremely common among the Bantu people in Southern Africa (Walker and Arvidsson, 1953; Bothwell and Finch, 1962). The major source of the excessive dietary iron is the home-brewed alcoholic beverages which are consumed in quantity by many adult males (Walker and Arvidsson, 1953 ; Bothwell et al., 1964a). It is consequently this section of the population which shows the highest incidence of severe iron overload (Bothwell and Isaacson, 1962). Scurvy is also common among the Bantu. As in other parts of the world it is seasonal, the highest incidence being at the end of winter and in early spring (Seftel et al., 1966). It is most commonly seen in adult males, and is very rare in children, though other deficiency diseases, such as kwashiorkor, are often encountered (Trowell, 1960).

There is now a considerable amount of evidence indicating that severe iron overload contributes to the development of scurvy in the adult Bantu population. For example, it has been shown that patients presenting with scurvy are invariably heavily siderotic (Bothwell et al., 1964b; Seftel et al., 1966). Moreover, the concentrations of ascorbic acid in the leucocytes of non-scorbutic individuals with no clinical evidence of scurvy

- From the Council for Scientific and Industrial Research, Iron and Red Cell Metabolism Group, Department of Medicine, University of the Witwatersrand Medical School, Johannesburg, South Africa.

t Research Fellow.

S Skilled Technologist.

F Physician.

Physician. Experimental and Clinical Pharmacology, University of the Witwaterstand

Professor of Medicine, University of the Witwaterssand.

This work was supported by a grant (AM04912-07) from the National Institutes of Health, U.S A. 